\title{
Modification of atherosclerosis by agents that do not lower cholesterol
}

\author{
John G F Cleland, Dennis M Krikler
}

In patients who already have clinical evidence of coronary atherosclerosis there is now clear evidence that several different lipid lowering agents can delay or even reverse the atherosclerotic process reducing the incidence of cardiovascular events and delaying mortality. ${ }^{12}$

However, the relation between atherosclerotic events and the blood cholesterol is poor in practical clinical terms, even though a strong statistical relation exists. More detailed measurements of high and low density lipoproteins and a series of apolipoproteins have strengthened the relation of the lipid profile to clinical events but, with the possible exception of high density lipoprotein cholesterol, have not yet stood the test of time to confirm that they are of real use to the clinician in accurately identifying patients at risk. This suggests that factors other than conventional measures of lipid metabolism may be important in the development of atherosclerosis.

Acetylation or oxidation of lipids accumulating in the intima is an essential part of the atherosclerotic process, attracting migrating macrophages, enabling them to take up lipids via scavenger receptors, and resulting in the formation of foam cells. ${ }^{34}$ Plaque growth also involves smooth muscle cell proliferation and collagen deposition. Foam cell death results in the formation of a core of lipid "gruel". Intraplaque haemorrhage and thrombosis are probably the major events leading to rapid plaque expansion: an occurrence that may or may not be clinically apparent. Indeed the incidence of myocardial infarction may be better related to enhanced blood coagulability than to raised blood cholesterol. ${ }^{5}$ Calcium accumulates usually in areas of cell necrosis and this accumulation may be the final step leading to cell death. However, it is not clear what, if any, pathogenic role calcium has in plaque growth.

Increased understanding of the mechanisms of the development of atherosclerotic plaques suggests several therapeutic targets other than modifying the concentrations of circulating lipids. Antioxidants could reduce the oxidative transformation of lipids and thereby prevent the appearance of foam cells. Growth factor inhibitors and antimitotic agents could prevent smooth muscle cell proliferation. Antithrombotic agents could prevent thrombosis, though potentially increasing the risk of plaque haemorrhage. Calcium antagonists could prevent calcium accumulation within the plaque. Other factors such as modulation of sympathetic activity and alterations in membrane charge can be $\stackrel{\overparen{\circ}}{\circ}$ manipulated and could alter atherogenesis. Finally, "crude" mechanical effects such as vasodilatation and increased blood flow either. down the vessel or through the nutrient vasa $\omega$ vasorum or reduced heart rate and therefore $\frac{\rho}{\partial}$ frequency of mechanical stress should not be? discounted.

The clinician may have an academic inter- -1 est in those processes that lead to atheroma formation but will remain sceptical of theiro practical relevance until theory is translated is into a reduction in vascular events in patients. $A$ Animal models are of limited relevance, espe-응 cially those in which lipid plaques are induced $\rightarrow$ by force feeding high cholesterol diets to herbivorous animals that normally have very little cholesterol in the diet. The histology of the lipid plaques induced in such animals is $\vec{\theta}$ largely unknown and probably bears scant $\stackrel{\oplus}{\omega}$ relation to atheroma. ${ }^{6}$ Moreover, lipid staining in the aorta is usually reported, because this is expedient, rather than the impact on histologically proven atheroma. Also the relation between aortic and coronary $\frac{\mathbb{D}}{\mathbb{Q}}$ atheroma development may be poor. ${ }^{7}$ More complex models of atherosclerosis have been $\frac{9}{3}$ developed by selecting strains of animals genetically susceptible to atherosclerosis or by using techniques such as angioplasty to produce endothelial damage. Such models are $\stackrel{\overparen{D}}{\stackrel{D}{2}}$ more expensive and difficult to procure, are? studied relatively infrequently, and may still $\underline{3}$. be irrelevant to the human disease. ${ }^{7}$

Interpretation of studies on human coronary arteries are not without difficulty as 0 plaque only intrudes into the arterial lumen during the later stages of atheroma develop-을 ment and only then is visible on the coronary angiogram. ${ }^{3} \mathrm{Up}$ to $40 \%$ of the cross sectional area of the vessel must be replaced for this to happen. Reports of drugs preventing new lesion formation are almost certainly false.? Visual assessment of the coronary angiograme also depends on comparing normal with abnormal, but normality cannot be reliably ${ }_{+}^{+}$ identified. Changes in coronary vascular tone, physiological or pharmacological, and eccen- $\overrightarrow{\mathbb{D}}$ tric plaque formation create further difficul- $\frac{?}{\Phi}$ ties in assessing changes in coronary lesions.

Even clinical assessment can be criticised. An agent that reduces atherosclerosis but does not reduce thrombosis may not reduce the incidence of myocardial infarction in patients who already have substantial amounts of atherosclerosis. Such a treatment could nonetheless be very effective in preventing the initial development of atheroma but 
would only be proven to be effective in very long-term studies. Clinicians must be on their guard to distinguish between hypotheses based on experiments in the laboratory and clinically proven facts.

\section{Antioxidants}

The rate at which macrophages take up native low density lipoprotein (LDL) is limited by their low expression of the LDL receptor. ${ }^{4}$ This led to the discovery of alternative scavenger receptors that take up oxidised LDL. Oxidised LDL is chemotactic for circulating macrophages (both directly and by releasing factors from the endothelium), inhibits the motility of tissue macrophages, and is cytotoxic. Uptake of $\beta$ very low density lipoprotein (VLDL) by macrophages can occur in the absence of modification of lipid particles, giving the appearance of foam cells in the absence of oxidised LDL, but modified LDL is probably the more important pathway in foam cell formation.

\section{Vitamins and related compounds}

POTENTIAL MECHANISMS OF ACTION

In cell culture high concentrations of vitamin $\mathrm{E}$, vitamin $\mathrm{C}, a$ tocopherol, and $\beta$ carotene prevent oxidation of LDL by smooth muscle or endothelial cells. However, the efficiency of these antioxidant effects seem to be subject to great inter-individual variation. ${ }^{8}$

\section{ANIMAL MODELS}

Several studies have examined the effects of vitamins $A, C$, and $E$, all of which have antioxidant properties on animal models as mundane as the cholesterol-fed rabbit and as exotic as the Japanese quail. ${ }^{9}$ These studies showed conflicting evidence of benefit or, in some experiments, harm. ${ }^{10}$ This may be due in part to individual variation in vitamin $\mathrm{E}$ dependent and independent oxidative resistance. Vitamin $\mathrm{E}$ reduced serum cholesterol in some, but not all, studies. ${ }^{112}$ Vitamin C seems to be a weak lipid antioxidant but may reduce oxidised vitamin $\mathrm{E}$, rendering it more effective. $\beta$ Carotene has pro-oxidant as well as antioxidant properties, and despite its incorporation into human LDL particles has been shown not to reduce their susceptibility to oxidation. ${ }^{13}$

\section{HUMAN STUDIES}

Studies have shown an inverse relation between the average plasma concentrations of antioxidant vitamins and the incidence of coronary disease in different populations. ${ }^{14-16}$ A diet high in polyunsaturated fats or low in essential fatty acids such as oleic acid, unprotected by high concentrations of antioxidants such as selenium and $a$ tocopherol may also predispose to atheroma formation ${ }^{17}{ }^{18}$. Hypertension could also predispose to reduced intimal antioxidant concentrations. ${ }^{19}$

Reports of benefits with antioxidant treatment are largely anecdotal. A preliminary report from the Harvard Physician's Heart
Study suggests that $50 \mathrm{mg}$ of $\beta$ carotene administered on alternate days may reduce serious cardiovascular events by around $50 \%{ }^{20}$ Likewise a low fat diet that is rich in vitamins $\mathrm{A}, \mathrm{C}$, and $\mathrm{E}$ may reduce reinfarction and mortality more than a low fat diet alone after an initial infarct. ${ }^{21}$

More rational treatment using antioxidants awaits a proper understanding of the mechanisms that lead to lipid peroxidation.

\section{Probucol}

POTENTIAL MECHANISMS OF ACTION

Probucol is highly lipid soluble and is incorporated into lipoproteins rendering them less susceptible to oxidation, thereby reducing their uptake by macrophages. Probucol may also inhibit cell-mediated oxidation of LDL, ${ }^{22}$ and it reduces both LDL and HDL cholesterol through interfering with lipid metabolism in various other ways. ${ }^{4}$

\section{ANIMAL STUDIES}

Evidence for an anti-atherosclerotic effect of probucol in the cholesterol fed rabbit is conflicting, ${ }^{23} 24$ though in the Watanabe heritable hyperlipidaemic rabbit it has consistently reduced the extent of lipid plaque ${ }^{52526}$ and seems more effective than lovastatin in this respect, ${ }^{25}$ despite the fact that probucol was less effective in reducing cholesterol. The relation between the effects on lipid plaque and the effects on atherosclerosis is unclear as stated above.

Probucol has been reported to cause regression of tendon xanthomata. ${ }^{27}$ Studies are underway ${ }^{28}$ to determine whether probucol can alter the course of femoral artery atherosclerosis in humans; preliminary results may be available soon.

\section{Calcium antagonists}

POTENTIAL MECHANISMS OF ACTION

Changes in intracellular calcium concentration are a ubiquitous signalling system associated with many of the processes of atherosclerosis and such changes have been taken as a rationale for using calcium antagonists to retard atheroma progression. Thankfully, calcium antagonists have a relatively specific effect on calcium transport in a small sub-population of ion channels; if they were more promiscuous they would be lethal.

Calcium antagonists could potentially interfere with atherogenesis by several mechanisms including (a) reduced accumulation of calcium within cells and the vascular wall, (b) interfering with lipid metabolism, (c) reducing intimal permeability to lipids, (d) antioxidant effects, (e) reduced collagen synthesis and smooth muscle cell proliferation, $(f)$ inhibition of platelet aggregation, $(g)$ reduction in arterial pressure.

Verapamil inhibits vascular calcification induced by vitamin $\mathrm{D}^{3}$, and the increase in vascular wall calcium in spontaneously hypertensive rats. ${ }^{29}$ Lipid soluble factors, such as vitamin $\mathrm{D}^{3}$, accumulate within foam cells and 
this could increase cellular calcium content and lead to cell death. ${ }^{3}$ Human plaque, unlike plaque in the cholesterol fed rabbit, contains a high proportion of calcium, but the relation of arterial calcification to atherogenesis, as opposed to arteriosclerosis, remains obscure.

Calcium antagonists can interfere with lipid metabolism in atherosclerotic plaque in various ways, ${ }^{30}$ including increased LDL receptor synthesis and cholesterol uptake, inhibition of lysosomal degradation of lipoprotein and hydrolysis of cholesteryl ester, and a reduction in acylcoenzyme A (ACAT)mediated cholesterol esterification. These processes may lead to further accumulation of lipid in macrophages that could be deleterious, especially as unesterified cholesterol is more toxic than the esterified form. However, dihydropyridine calcium antagonists may also increase the efflux of unesterified cholesterol from foam cells, possibly by increasing cholesterol hydrolysis, thereby reducing the chance of cell death. Verapamil may have additional effects such as blocking the delivery of cholesterol to ACAT thereby reducing cholesterol esterification and intracellular lipid accumulation. ${ }^{31}$ Reports that calcium antagonists change the lipid profile are controversial but suggest that they have a neutral or slightly beneficial effect. ${ }^{32}$

Calcium antagonists reduce intimal permeability to cholesteryl ester (an effect that has been attributed to an amelioration of free radical damage ${ }^{31}$ ) and exert antiperoxidative effects on lipids. ${ }^{33}{ }^{34}$ Calcium antagonists can inhibit the proliferation of intimal and vascular smooth muscle cells ${ }^{35} 36$ and collagen deposition. Calcium antagonists may reduce platelet aggregability that could inhibit plaque growth as well as thrombus formation. ${ }^{37}$

Calcium antagonists are very effective at lowering blood pressure though their ability to prevent the complications of hypertension has not been formally tested. A reduction in blood pressure and antagonism of increases in vascular tone at the site of defective endothelium, mediated by agents such as endothelin, could reduce atherogenesis. However, several animal models have suggested that atheroma may be prevented even if blood pressure is unaffected. Verapamil could also have a beneficial effect by reducing heart rate. ${ }^{38}$

Many of the above studies have been conducted in vitro with concentrations that would not be tolerated in animals, and in animals in concentrations that would not be tolerated by humans. Their relevance to clinical practice is therefore dubious.

\section{ANIMAL MODELS}

Numerous experimental models in rabbits, pigs, and monkeys force fed cholesterol or with heritable hyperlipidaemia have shown that the dihydropyridine calcium antagonists can have a powerful effect on reducing lipid deposition in the aorta. ${ }^{31} 3439$ However, others have been unable to confirm these results ${ }^{4041}$ in similar models. Moreover, agents that reduce aortic lipid deposition may not have similar effects on the coronary arteries. ${ }^{7}$
Adding these controversies to those of the precise significance of aortic lipid deposition in relation to atherosclerosis should induce a healthy degree of scepticism.

\section{Dihydropyridine calcium antagonists}

\section{HUMAN STUDIES}

In contrast to the small numbers of animals treated experimentally there are several large 흠 well controlled studies of dihydropyridine cal- $\frac{\bar{m}}{\bar{b}}$ cium antagonists in patients with minor coro- $\stackrel{\oplus}{\varrho}$ nary artery disease, after myocardial $ڤ$ infarction both short and long term, and in $\overrightarrow{0}$ unstable angina and in heart failure. ${ }^{42-50}$. These studies have consistently failed to show $\overrightarrow{\vec{\omega}}$ a reduction in myocardial infarction or mortality, rather the reverse.

Two well controlled studies did not show any significant overall effect of the dihydropy- $-\overrightarrow{ }$ ridine calcium antagonists nifedipine and nicardipine on the progression of coronary음 artery disease..$^{46}$ The INTACT study sug-is gested a reduction in the appearance of new $\perp$ lesions by about $28 \%$ that just achieved sta-응 tistical significance. ${ }^{46}$ The study by Waters et al suggested that lesions of $<20 \%$ (lesions $<\stackrel{\text { g }}{2}$ $20 \%$ were considered not to be definite? stenoses in the INTACT study) were half as likely to progress if the patient was treated $\vec{\bullet}$ with nicardipine. ${ }^{47}$ The fact that the findings $\stackrel{\oplus}{\oplus}$ were made independently argues for a real effect. However, these findings may have occurred by chance owing to the numerous comparisons made within the studies, and the possibility of artefact should be considered. $A \stackrel{\circ}{\otimes}$ coronary stenosis may appear less severe in a dilated vessel if the atheromatous plaque is $\frac{3}{3}$ eccentric and the segment can relax. The INTACT study had an all cause mortality of 12 on nifedipine but only 2 on placebo ( $\mathrm{p}<\frac{3}{3}$ $0.05)$, which is worrying. Although the mortality in the study by Waters et al was not? increased by nicardipine there were $17 \frac{3}{3}$. infarcts in the active group versus nine in the control-again a trend in the wrong direction. The excess of events in the active groupso make it difficult to interpret the small angiographic benefits. Other studies suggesting a을 beneficial effect of calcium antagonists include a small uncontrolled study by Loaldi ${ }^{\circ}$ et $a l^{49}$ and a study on coronary saphenous 0 vein grafts by Gottlieb et al. ${ }^{50}$

The study of Gottlieb et al suggested that nifedipine could reduce the rate of grafte occlusion and the appearance of graft stenosis with the use of nifedipine in the first year.? Graft occlusion at this early stage is usually caused by thrombosis rather than atheroma ब्ञ and irregularities in the vein graft may be bet- $\frac{}{\Phi}$ ter related to intrinsic irregularities of the graft or to subclinical thrombotic episodes. Improved distal run-off, graft vasodilatation and improved flow induced by nifedipine mays well be valuable in preventing thrombosis and흑 be of clinical benefit, but this may be poorly? related to native artery atherosclerosis or late vein graft stenosis that does have all the appearances of atheroma. 


\section{Verapamil and diltiazem}

HUMAN STUDIES

There is only one major outcome trial of diltiazem in humans. ${ }^{51}$ This study in patients after myocardial infarction showed no overall effect on mortality. Those patients with heart failure did worse with diltiazem treatment, ${ }^{52}$ and exclusion of this group from analysis suggested that outcome may have been improved in the remaining participants. Two large postinfarction studies with verapamil have been reported..$^{5354}$ These showed a trend to reduced mortality, that became significant if patients with heart failure were excluded from analysis. All three studies indicated a reduction in recurrent myocardial infarction with these agents.

A study examining the effects of verapamil on the progress of minor coronary disease is being conducted by Kober et al and should report soon. ${ }^{55}$

\section{B Blockers}

POTENTIAL MECHANISMS OF ACTION

$\beta$ Adrenoceptor antagonists increase blood cholesterol and triglycerides and reduce HDL cholesterol and this has been cited as evidence that they may be atherogenic. However, it is far from clear that these adverse changes in the lipid profile induced by a $\beta$ adrenoceptor antagonist are harmful.

$\beta$ Adrenoceptor antagonists increase the cholesterol content of cultured macrophages and smooth muscle cells as does serum obtained from patients treated with a $\beta$ blocker. $^{56} \beta$ Adrenoceptor antagonists may also stimulate proliferation of smooth muscle cells cultured from human aortic intima. ${ }^{57}$

\section{ANIMAL MODELS}

In rabbits subjected to aortic endothelial injury, propranolol increased neointimal thickening, lipid accumulation, cellular proliferation, and collagen content. ${ }^{56}$ In contrast, $\beta$ adrenoceptor antagonists retarded the deposition of aortic lipid in the cholesterol fed rabbit and monkey. ${ }^{385859} \beta$ Blockers also reduced endothelial injury related to sympathetic arousal caused by the social disruption of male monkeys. ${ }^{38}$

Increased sympathetic activity can increase intimal permeability to cholesteryl esters: this can be reversed by $\beta$ blockers. ${ }^{60} \beta$ Blockers also reduce ACAT activity and catecholamine induced platelet aggregability ${ }^{60}$ and decrease LDL's affinity for arterial wall proteoglycans that may predispose to atheroma. ${ }^{61}$

\section{HUMAN STUDIES}

One small poorly controlled study suggested that new coronary lesions and progression of existing lesions was more likely with propranolol than with nifedipine. ${ }^{49}$

$\beta$ Blockers have an established place in reducing mortality and reinfarction after myocardial infarction. A specific effect of $\beta$ blockers in reducing cardiovascular events to a greater extent than thiazide diuretics in patients with hypertension is controversial, and was not confirmed in elderly patients. ${ }^{6263}$

Consideration of the similar benefits of verapamil and the $\beta$ blockers after myocardial infarction, at least in the absence of heart failure, suggest that heart rate reduction might be the cause of the reduction in cardiovascular events. Limitation of increases in heart rate is obviously a powerful way of reducing myocardial ischaemia and may reduce atherogenesis. Atheromatous lesions are most likely to develop at the bifurcation of vessels at points where the vessel wall is exposed to high shear stress to the intima and possibly to greater mechanical stress of the vessel wall. Reductions in myocardial oxygen demand and therefore blood flow may reduce shear stresses. Reduction in the frequency of cardiac contraction may reduce the mechanical stress on the coronary vessel walls.

\section{$a_{1}$ Adrenoceptor antagonists}

POTENTIAL MECHANISMS OF ACTION

$\alpha_{1}$ Adrenoceptor antagonists reduce total serum cholesterol, increase the $\mathrm{HDL} /$ total cholesterol ratio, and reduce serum triglycerides in humans. The effect of these favourable changes in the lipid profile on human atherosclerosis is unknown.

In cultured human fibroblasts high concentrations of $\alpha_{1}$ adrenoceptor antagonists increased LDL receptor activity ${ }^{64}$ possibly as a homoeostatic response to reduced intracellular cholesterol synthesis. ${ }^{65}$

$\alpha_{1}$ Adrenoceptor antagonists also reduced dietary cholesterol absorption in the Cynomolgus monkey. ${ }^{60}$

ANIMAL MODELS

In Golden Syrian hamsters fed a moderately high cholesterol diet doxazosin reduced both lipid accumulation in the aorta and the density of foam cells in the lesions by $>50 \%$, an effect that was similar to that of cholestyramine in the same model. ${ }^{67}$ Hepatic cholesterol synthesis was reduced in this model by reductions in HMG CoA reductase activity, ${ }^{68}$ while increases in lipoprotein lipase may reduce serum VLDL and triglyceride concentrations. ${ }^{69}$

\section{ACE inhibitors}

Angiotensin II is a potent vasoconstrictor and pressor agent and stimulates smooth muscle cell proliferation and hypertrophy either directly or through the production of platelet derived growth factor. ACE inhibitors also seem capable of preventing myointimal proliferation after vascular injury, presumably by reducing angiotensin $\mathrm{II},{ }^{70}$ though an effect of increased bradykinin has not been excluded.

Captopril contains an - $\mathrm{SH}$ group that may act as a free radical scavenger, not only reducing intimal permeability to lipoproteins but also the peroxidation of intimal lipids.

\section{ANIMAL STUDIES}

Captopril has been reported by Aberg et al to retard dramatically the progress of atheroma 
in the carotid and coronary arteries of Cynomolgus monkeys. ${ }^{71}$ Aberg et al considered that this was not simply due to a reduction in arterial pressure, because nifedipine had not retarded the progression of atheroma in a similar model despite a hypotensive effect. ${ }^{41}$

However, the evidence for an anti-atherosclerotic effect in rabbits is conflicting ${ }^{72} 73$ and the doses of drug used (up to $50 \mathrm{mg} / \mathrm{kg} / \mathrm{a}$ day of captopril) are not in clinical use.

\section{HUMAN STUDIES}

Data from both the treatment and prevention arms of the SOLVD study and from SAVE indicate a reduction in hospital admissions for angina, and in fatal and non-fatal myocardial infarction. ${ }^{74-76}$ This has been interpreted as an anti-ischaemic effect of ACE inhibitors. Properly designed clinical trials have not shown convincing evidence of an anti-anginal effect of ACE inhibitors and indeed there is some evidence that they make angina worse if the arterial and therefore coronary perfusion pressure drops significantly. ${ }^{77}$ The apparent contradiction can be resolved by postulating that while ACE inhibitors have little antianginal efficacy they can prevent the progress of atherosclerosis, reducing the likelihood of unstable angina, myocardial infarction, and ultimately death.

\section{Nitrates}

The function of the endothelium adjacent to an atherosclerotic plaque is abnormal. It does not release endothelium-derived relaxing factor and this, in turn, has been considered by some to contribute to the development of atherosclerosis.

Isosorbide dinitrate can inhibit platelet aggregation. However, nitrates do not seem to exert antiatherogenic actions in cell culture. Data from one small study suggested no evidence that long-term treatment with nitrate retards the angiographic progression of coronary disease or reduces cardiovascular morbidity or mortality. ${ }^{49}$

\section{Ketanserin}

A large clinical trial conducted in patients with intermittent claudication showed no reduction in cardiovascular events with this serotonin antagonist. ${ }^{78}$

\section{Antithrombotic agents}

Over a century ago Rokitansky hypothesised that thrombosis contributed substantially to the generation of atherosclerosis. ${ }^{79}$ The suggestion that the residual coronary stenosis at the site of occlusion is less severe if the patient undergoes thrombolysis supports the contention that plaque rupture and thrombosis is an important determinant of progression of atherosclerosis. ${ }^{80}$ It is likely that most coronary thrombotic events are not clinically apparent probably because they do not completely occlude the coronary artery. Organisation of the thrombus and neo- endothelialisation lead to incorporation of the thrombus in the arterial wall and the rapid progression of atheroma. This would explain why atheroma often rapidly progresses focally while remaining stable in other parts of the ${ }_{I}$ coronary tree.

\section{Aspirin}

POTENTIAL MECHANISMS OF ACTION

Aspirin inhibits thrombosis only if thrombox-들 ane $A_{2}$ formation by platelets plays a major $\frac{\bar{c}}{5}$. part in the growth of thrombi: aspirin has lit- $\stackrel{\oplus}{\varrho}$ tle effect on thrombosis when thrombin generation and fibrin formation are dominant $\vec{\circ}$ factors. ${ }^{81}$ Aspirin is not effective in preventing single-layer platelet adherence to damaged $\vec{\omega}$ endothelium but may prevent further platelet $\frac{\rho}{\partial}$ aggregation. The absence of an effect on the? adherence of a platelet monolayer to the injured endothelium has been cited as evi- $\overrightarrow{+}$ dence that aspirin is unlikely to have a specific effect in preventing the development of atheroma, ${ }^{82}$ though limitation of the extent of $\bar{c}$ platelet aggregates could still be important. S Aspirin does not prevent smooth muscle and응 intimal hyperplasia in coronary vein grafts, ${ }^{82}-$ despite the fact that aspirin would be expect-⿳亠丷厂 ed to inhibit platelet derived growth factor? (PDGF) release, which is a powerful stimulus to smooth muscle cell proliferation.

Theoretically aspirin could accelerate the progression of atheroma by inhibiting prostacyclin formation. ${ }^{83}$

\section{ANIMAL MODELS}

A sophisticated model of atherosclerosis inळ్ pigs suggests that aspirin may prevent the new appearance of atheroma and retard its 3 progression. ${ }^{82}$ In autologous cephalic vein grafts inserted into femoral arteries inọ macaque monkeys with and without hyperlipidaemia, aspirin reduced the lipid content of the graft wall. ${ }^{84}$

\section{HUMAN STUDIES}

Whereas aspirin is clearly effective in reducing mortality when prescribed within the firsto few weeks after a myocardial infarction or for $>$ unstable angina, the benefit declines sharply을. the greater the interval from the index event. N Patients with cerebrovascular disease have an increased incidence of coronary events, and aspirin reduces the risk of myocardial infarc- $-\omega$ tion by around $35 \% 85$ in such patients? However, it is not clear whether aspirine retards the progress of atherosclerosis in addition to diminishing the risk of thrombotic.+ occlusion.

One preliminary communication has sug

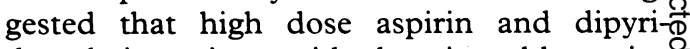
damole in patients with chronic stable angina reduce the likelihood of myocardial infarction by about $50 \%$ and reduced the incidence of new lesions on angiography. ${ }^{86}$

The UK doctors study found no reduction in coronary or cerebral vascular events when aspirin prophylaxis was used for primary prevention. ${ }^{87} \mathrm{~A}$ study of similar statistical power (determined by the number of events not the 
number of participants) conducted in the United States implied that aspirin could reduce the risk of myocardial infarction by about $50 \%{ }^{88}$ However, aspirin had no effect on overall cardiovascular mortality. This apparent discrepancy was largely due to an excess of sudden deaths in the aspirin treated group, a mode of death that was included with myocardial infarction in the British study. In the United States study the ratio of non-fatal to fatal myocardial infarction was about 10:1 whereas in the British study it was 1:1. These disparities are unexplained.

A follow up of the United States study on primary prevention has indicated that the effect of aspirin in reducing myocardial infarction begins soon after start of treatment and the magnitude of the effect does not increase with time, implying no reduction in the development of atheroma ${ }^{89}$ but rather an effect on thrombotic occlusion. However, studies on peripheral vascular disease have suggested that aspirin may retard the progress of atheroma. ${ }^{90}$

\section{OTHER ANTI-PLATELET AGENTS}

In general the addition of dipyridamole to aspirin did not further reduce vascular complications compared with aspirin alone in clinical studies of cerebral or peripheral vascular disease. ${ }^{89}$ Ticlopidine showed promise in several recent studies of patients with peripheral vascular disease. It reduced total and cardiac mortality and retarded the angiographic progression of peripheral vascular disease. ${ }^{91} 92$

Inhibition of thrombin-mediated platelet aggregation may prove a more powerful method of retarding atheroma formation than aspirin.

\section{Heparin}

POTENTIAL MECHANISMS OF ACTION

Substances closely allied to heparin are a normal constituent of the endothelium and may form part of the natural defence against thrombosis. Heparin can restore the electronegativity of the damaged intima ${ }^{93}$ prevent endothelial damage by various compounds, including histamine, angiotensin, and bacterial endotoxin, ${ }^{94}$ and has antioxidant properties. Heparin reduces the uptake into the vascular wall of LDL, which is normally anionic at physiological $\mathrm{pH}^{95}$ Heparin neutralises lysosomal cationic proteins released by leucocytes and limits the activation of complement, ${ }^{96}$ which may be responsible for endothelial damage leading to atherosclerosis. Heparin reduces thrombin formation, enhances its inactivation by antithrombin, and inhibits thrombin enhanced platelet adhesion to the damaged intima. ${ }^{97}$ Heparin enhances the production of prostacyclin in diseased coronary arteries. ${ }^{98}$ Heparin also inhibits hyperplasia of the smooth muscle cells stimulated by PDGF. Heparin reduces blood coagulation, enhances fibrinolysis, ${ }^{99}$ increases circulating HDL, ${ }^{100}$ and may lower concentrations of circulating triglycerides. ${ }^{101}$
ANIMAL MODELS

Heparin can prevent and even reverse the deposition of lipid in the aorta in cholesterol fed rabbits. ${ }^{102}$

\section{HUMAN STUDIES}

As long ago as 1956 Engelberg reported that intermittent treatment with heparin could reduce vascular complications in patients with atherosclerosis. ${ }^{103}$ Several other investigators have reported that low dose long-term heparin reduced vascular complications in patients with coronary artery disease. ${ }^{104} 105$

Neri Serneri et al compared the effects of long-term (23 months) low dose (12 $500 \mathrm{IU}$ once daily) heparin and placebo in 728 patients after myocardial infarction. ${ }^{106}$ Heparin achieved a reduction in total mortality of borderline statistical significance (34\% reduction by intention to treat and $48 \%$ on an on-treatment analysis) and reinfarction was reduced by $63 \%$. Inhalation of heparin by nebuliser seems to be an effective, feasible and more acceptable alternative to subcutaneous injection and may need to be administered as infrequently as once every two weeks. ${ }^{102} 107$

\section{Warfarin}

POTENTIAL MECHANISMS OF ACTION

The incidence of coronary events is as, or more, closely related to plasma concentrations of factor VII activity and fibrinogen than to cholesterol. Warfarin considerably reduces factor VII activity. Reduction in nonocclusive thrombotic events could retard the rapid progress of atheroma. Reduction of occlusive events may lead to reductions in the incidence of sudden death and myocardial infarction.

\section{ANIMAL STUDIES}

More information is needed on the effect of warfarin in animal studies.

\section{HUMAN STUDIES}

There is clear evidence of major benefit for formal anticoagulation as secondary prophylaxis for stable angina ${ }^{108}$ and myocardial infarction. ${ }^{109110}$ Warfarin reduces overall mortality by around $35 \%$, reinfarction by about $45 \%$, and stroke by $60 \%$ when its administration is started late after myocardial infarction. In the Dutch reinfarction study the mean time between the randomised withdrawal of warfarin and the earlier index myocardial infarction was 2 years.

A study of low dose warfarin or aspirin or both with a factorial design is underway to determine whether such strategies can delay or prevent coronary events in men at high risk of coronary events. ${ }^{111}$

\section{Conclusion}

Atherosclerosis is a complex chronic disease that is characterised by sudden spurts of growth and catastrophic vascular occlusion. It is unlikely that one intervention will be effec- 
tive in preventing the progress of atheroma at all stages of the disease, apart perhaps from the cessation of smoking. Lowering lipids, reduction in blood pressure, and use of antioxidants seem the most likely effective interventions very early in the progress of the condition, and antithrombotic agents seem most likely to be useful in preventing clinical and subclinical thrombosis leading to sudden plaque expansion.

Large scale studies are underway to investigate the effect of most of the agents discussed above on the progression of atheroma. Notable exceptions, as far as we are aware, are $a$ blockers and heparin

New, designer drugs will be developed to interfere with specific aspects of the generation of atheroma such as growth factors, cytokines, and adhesion molecules. The major problem in drug development is not candidate drugs or theories but developing an adequate animal model of the disease process and the cost of establishing benefit whether this be in animal models or in primary or secondary prevention in humans.

1 Carlson LS, Rosenhamer G. Reduction of mortality in the Stockholm Ischaemic Heart Disease Secondary Prevention Study by combined treatment with clofibrate and nicotinic acid. Acta Med Scand 1988;223:405-18.

2 Blankenhorn DH. Blood lipids and human coronary artery atherosclerosis regression: the angiographic evidence. Current Opinion in Lipidology 1991;2:234-9.

3 Davies MJ, Krikler DM, Katz D. Atherosclerosis: inhibition or regression as therapeutic possibilities. Br Heart $f$ 1991;65:302-10

Steinberg D. Antioxidants and atherosclerosis: a curren assessment. Circulation 1991;84:1420-5.

5 Meade TW, Mellows S, Brozovic M, et al. Haemostatic function and ischaemic heart disease: principal results of the Northwick Park Heart Study. Lancet 1986;ii:533-7.

6 Stehbens WE. An appraisal of cholesterol feeding in experimental atherogenesis. Prog Cardiovas Dis 1986;29: $107-28$

7 Ginsburg R, Davis K, Bristow M, et al. Calcium antagonists suppress atherogenesis in aorta but not in the intra-mural coronary arteries of cholesterol-fed rabbits. Lab Invest 1983;49:154-8.

8 Esterbauer H, Puhl H, Dieber-Rotheneder M, Waeg G, Rabl H. Effect of antioxidants on oxidative modification of LDL. Ann Med 1991;23:573-81.

9 Chisholm GM. Antioxidants and atherosclerosis: a current assessment. Clin Cardiol 1991;14:25-30.

10 Godfried SL, Coombs GF Jr, Saroka JM, Dillingham LA. Potentiation of atherosclerotic lesions in rabbits by a high dietary level of vitamin E. Br $\mathcal{F}$ Nutr 1989;61: 607-17.

11 Williams RJ, Motteram JM, Sharp CH, Gallagher PJ. Dietary vitamin $\mathrm{E}$ and the attenuation of early lesion Dietary vitamin $\mathrm{E}$ and the attenuation of early lesion
development in modified Watanabe rabbits. development in modified

12 Smith TL, Kummerow FA. Effect of dietary vitamin E on plasma lipids and atherogenesis in restricted ovulato chickens. Atherosclerosis 1989;75:105-9.

13 Steinberg D. Antioxidants in the prevention of human atherosclerosis: summary of Proceedings of the National Heart, Lung, \& Blood Institute Workshop: September 5-6 1991, Bethesda, Maryland. Circulation 1992;85 2383-443.

14 Gey KF, Puska P, Jordan P, Moser UK. Inverse correlation between plasma vitamin $E$ and mortality from ischemic heart disease in cross-cultural epidemiology. Am 7 Clin Nutr 1991;53:326-34.

15 Gey KF, Puska P. Plasma vitamins $E$ and $A$ inversely correlated to mortality from ischemic heart disease in cross-cultural epidemiology. Ann NY Acad Sci 1989 570:267-282

16 Gey KF, Stahelin HB, Puska P, Evans A. Relationship of plasma level of vitamin $C$ to mortality from ischemic heart disease. Ann NY Acad Sci 1987;498:111-23.

17 Kok FJ, van Poppel G, Melse J, Verhuel E, Scouten EG Kruyssen DH, Hofman A. Do antioxidants and polyunsaturated fatty acids have a combined association with coronary atherosclerosis? Atherosclerosis 1991;86:85-90.

18 Parthasarathy S, Khoo JC, Miller E, Barnett J, Witztum $\mathrm{JL}$, Steinberg D. Low density lipoprotein enriched in oleic acid is protected against oxidative modification: implications for dietary prevention of atherosclerosis. Proc Natl Acad Sci USA 1990;87:3894-8.

19 Hunter GC, Dubick MA, Keen CL, Eskelson CD.
Effects of hypertension on aortic antioxidant status in human abdominal aortic aneurysmal and occlusive disease. Proc Soc Exp Biol Med 1991;196:273-9.

20 Gaziano JM, Manson JE, Ridker PM, Buring JE Hendnnekens CH. Beta carotene for chronic stable angina. Circulation 1990;82(Suppl III):202.

21 Singh RB, Rastogi SS, Verma R, Laxmi B, Singh R, W Ghosh S, Niaz MA. Randomised controlled trial of car- $T$ dioprotective diet in patients with recent acute myocardial infarction: results of one year follow up. $B M \mathcal{F}$ 1992;304:1015-9.

22 Parthasarathy S. Evidence for an additional intracellular site of action of probucol in the prevention of oxidative modification of low density lipoprotein: use of a new water-soluble probucol derivative. $\mathcal{f}$ Clin Invest 1992. 89:1618-21.

23 Stein Y, Stein O, Delplanque B, Fesmire JD, Lee DM, Alaupovic P. Lack of effect of probucol on atheroma formation in cholesterol-fed rabbits kept at comparable formation in cholesterol-fed rabbits kept at comparable plasma

24 Daugherty A, Zweifel BS, Schonfeld G. Probucol attenuates the development of aortic atherosclerosis in choles- $\vec{O}$ terol-fed rabbits. Br $\mathcal{F}$ Pharmacol 1989;98:612-8.

25 Carew TE, Schwenke DC, Steinberg D. Antiatherogenic effect of probucol unrelated to its hypocholesterolemic effect: evidence that antioxidants in-vivo can selectively inhibit low density liporotein degradation in macrophage-rich fatty streaks slowing the progression of atherosclerosis in the WHHL rabbit. Proc Natl Acad Sci USA 1987;84:7725-9.

26 Kita $T$, Nagano $Y$, Yokode $M$, Ishii $K$, Kume $N$, $\mathcal{C}$ Ooshima A, et al. Probucol prevents the progression of atherosclerosis in Watanabe heritable hyperlipidaemic rabbit, an animal model for familial hypercholes terolemia. Proc Natl Acad Sci USA 1987;84:5928-31.

27 Yamamoto A, Mastuzawa Y, Yokoyama S, Funahashi T, U Yamamura T, Kishino BI. Effects of probucol on xanthomata regression in familial hypercholesterolaemia. Am $\mathcal{F}$ Cardiol 1986;57:29-35.

28 Walldius G, Carlson LA, Erikson U, Olsson AG, Johansson J, Molgaard J, Nilsson S, Stenport G, Kaijser L, Lassvik C, Holme I. Development of femoral atherosclerosis in hypercholesterolemic patients during treatment with cholestyramine and probucol/placebo: ment with cholestyramine and probucol/placebo:
Probucol Quantitative Regression Swedish Trial (PQRST) - a status report. Am f Cardiol 1988;62: 37-43.

29 Fleckenstein-Grun G, Frey M, Thimm F, Luley C, Czirfusz A, Fleckenstein A. Differentiation between calcium- and cholesterol-dominated types of arteriosclerotic lesions: antiarteriosclerotic aspects of calcium antagonists. F Cardiovasc Pharmacol 1991;18 (suppl 6):1-9.

30 Armstrong ML, Heistad DD, Lopez JAG. Regression of $\frac{O}{\mathbb{D}}$ atherosclerosis. A role for calcium antagonists. $\mathrm{Am} \mathrm{f} \mathrm{Q}$ Hypertens 1991;4:5035-115.

31 Keogh AM, Schroeder JS. A review of calcium antagonists and atherosclerosis. $f$ Cardiovasc Pharmacal nists and atherosclerosis.

32 Midtbo KA. Effects of long-term verapamil therapy on serum lipids and other metabolic parameters. $A m \mathcal{F}$ Cardiol 1990;66:13 I-15 I.

33 Noronha-Dutra AA, Steen-Dutra EM, Woolf N. An antioxidant role for calcium antagonists in the prevention of adrenaline mediated myocardial and endothelial damage. Br Heart f 1991;65:322-5.

34 Henry PD. Antiperoxidative actions of calcium antagonists and atherogenesis. 7 Cardiovasc Pharmacol 1991;18 (suppl 1):6-10

35 Woll E, Weiss $\mathrm{H}$, Waldegger S, Lang F. Effect of calcium channel antagonists on cell membrane potential $O$ oscillations and proliferation of cells expressing the ras oscillations and proliferation of cells expressing the ras $D$

6 Nilsson I, Sjolung M, Palmberg L, Von Euler AM, O Jonzon B, Thyborg I. The calcium antagonist nifedipine inhibits arterial smooth muscle cell proliferation. O Atherosclerosis 1985;58:109-12.

37 Ware JA, Johnson PC, Smith M, Saltzman EW. N Inhibition of human platelet aggregation and cytoplasmic calcium responses by calcium antagonists: studies with aequorin and quin-q. Circ Res 1986;59:39-42.

38 Kaplan JR, Petterson K, Manuck SB, Olsson G. Role of sympathoadrenal medullary activation in the initiation and progression of atherosclerosis. Circulation 1991;84 (suppl VI):23-32.

39 Henry PD, Calcium antagonists as antiatherosclerotic agents. Atherosclerosis 1990;10:963-5.

40 Stender S, Stender I, Nordestgaard B, Kjeldsen K. No O effect of nifedipine on atherosclerosis in cholesterol-fed $\mathbb{D}$ rabbits Arteriosclerosis 1984;4:389-94.

41 Ferrer P, Aberg G. Progression of atherosclerosis in cho- $Q$ lesterol-fed cynomolgus monkeys during treatment with $\sigma$ nifedipine [abstract], FASEB f 1990;4:1151.

42 Wilcox RG, Hampton JR, Banks DC, Birkhead JS, $尺$ Brooksby IAB, Burns-Cox CJ. Trial of early nifedipine 응 in acute myocardial infarction: the Trent study. $B M \mathcal{F}$ 1986;293:1204-7.

43 Holland Interuniversity Nifedipine/Metoprolol Trial (HINT) Research Group. Early treatment of unstable angina in the coronary care unit: a randomised, double blind placebo controlled comparison of recurrent ischaemia in patients treated with nifedipine or metoprolol or both. Br Heart f 1986;56:400-13. 
44 SPRINT-I Study Group. Secondary PreventionReinfarction Israeli Nifedipine Trial I. A randomised intervention trial of nifedipine in patients with acute intervention trial of nifedipine in patients with

45 SPRINT-II Study Group. The Secondary Prevention Reinfarction Israeli Nifedipine Trial II. Design methods and results. Eur Heart F 1988;9 (suppl 1):350.

46 Lichtlen PR, Hugenholtz PG, Rafflenbeul W, Hecker $\mathrm{H}$ Jost $S$, Deckers JW. Retardation of angiographic progression of coronary artery disease by nifedipine. Lancet 1990;335:1109-13.

47 Waters $D$, Lesperance J, Francetich $M$, Causey $D$, Theroux $\mathrm{P}$, Chiang $\mathrm{Y}-\mathrm{K}$, et al. A controlled clinical tria to assess the effect of calcium channel blocker on the progression of coronary atherosclerosis. Circulation 1940 82:1940-53.

48 Elkayam U, Amin J, Mehra A, Vasquez J, Weber I Rahimtoola $\mathrm{SH}$. A prospective, randomized, doubleblind, crossover study to compare the efficacy and safety of chronic nifedipine - therapy with that of isosorbide dinitrate and their combination in the treatment of chronic congestive heart failure. Circulation 1990 82:1954-61

49 Loaldi A, Polese A, Montorsi P, De Cesare N, Fabbiocchi F, Ravagnani P, Guazzi MD. Comparison of nifedipine, propranolol and isosorbide dinitrate on angiographic progression and regression of coronary arterial narrowings in angina pectoris. Am $f$ Cardiol 1989;64:433-39.

50 Gottlieb SO, Brinker JA, Mellits ED, Achuff SC, Baughman KL, Traill TA, et al. Effect of nifedipine on the development of coronary bypass graft stenosis in high-risk patients: a randomised double-blind, placebocontrolled trial [abstract]. Circulation 1989;80 (suppl 2): 228

51 Multicentre Diltiazem Postinfarction Trial Research Group. The effect of diltiazem on mortality and reinfarction after myocardial infarction. New Engl 7 Med 1988;319:385-92.

52 Goldstein RE, Bocuzzi SJ, Cruess D, Nattel S for the Multicentre Diltiazem Post-infarction Trial Research Group. Diltiazem increases late-onset congestive heart failure in post-infarction patients with early reduction in ejection fraction. Circulation 1991;83:52-60.

53 Danish Study Group on Verapamil in Acute Myocardial Infarction. Eur Heart f 1984;5:516-28.

54 Danish Study Group on Verapamil in Myocardial Infarction. Effect of verapamil on mortality and majo events after acute myocardial infarction. (The Danish Verapamil Infarction Trial II-DAVIT II.) $A m \mathcal{f}$ Cardiol 1990;66:779-85.

55 Kober G, Schneider W, Kaltenbach M. Can the progression of coronary sclerosis be influenced by calcium antagonists? F Cardiovasc Pharmacol 1989;13 (suppl 4): antagor

56 Orekhov AN, Andrianova IV, Rekhter MD, Tertov VV, Andreeva ER, Ragimov SE, Mironov AA. Beta-blockers: propranolol, metoprolol, atenolol, pindolol, alprenolol and timolol, manifest atherogenicity on in vitro, ex vivo and in vivo models. Elimination of propranolol atherogenic effects by papaverine. Atherosclerosis 1992;95:77-85.

57 Orekhov AN, Ruda M, Baldenkov GN, et al. Atherogenic effects of beta-blockers on cells cultured from normal and atherosclerotic aorta. $\mathrm{Am} f \mathrm{Cardiol}$ 1988;61:1116-7.

58 Ostlund-Lindqvist AM, Lindqvist P. Effect of metoprolol on diet-induced atherosclerosis in rabbits. Arteriosclerosis 1988;8:40-5.

59 Chobanian AV, Brecher P, Chan C. Effects of propranolol atherogenesis in the cholesterol-fed rabbit. Circ Res 1985;56:755-62.

60 Cruickshank JM, Smith JC. The beta-receptor, atheroma and cardiovascular damage. Pharmacol Ther 1989;42: 383-404.

61 Camejo G, Hurt E, Thubrikar M, Bondjers G. Modification of low density lipoprotein association with the arterial intima. A possible environment for the antiatherogenic action of beta-blockers. Circulation 1991; 84(suppl VI): $17-22$.

62 Wilhelmsen L, Berglund G, Elmfeldt D, et al. Betablockers versus diuretics in hypertensive men: main
results from the HAPPHY trial. $\mathcal{f}$ Hypertens $1987 ; 5$ : results

63 MRC Working Party. Medical Research Council trial of treatment of hypertension in older adults: principal results. $B M F$ 1992;304:405-12.

64 Leren TP. Doxazosin increases low density cholesterol receptor activity. Acta Pharmacol Toxicol 1985;56: 269-72.

65 d'Eletto RD, Javitt NB. Effect of doxazosin on cholesterol synthesis in cell culture. $\mathcal{f}$ Cardiovasc Pharmacol 1989;13(Suppl 2):5-1-54

66 Vespa DB, Stucchi AF, Nicolosi RJ. The effect of doxazosin, an alpha-1-antagonist on lipoprotein levels, low density lipoprotein metabolism and cholesterol absorption in hypocholesterolaemic monkeys. $f$ Drug Dev 1990;3:249-53.

67 Kowala MC, Nunnari JJ, Durham SK, Nicolosi RJ. Doxazosin and cholestyramine simlarly decrease fatty streak formation in the aortic arch of hyperlipidaemic hamsters. Atherosclerosis 1991;91:35-49.

68 Jansen H, Lammers R, Baggen MGA, Birkenhager JC. Effects of doxazosin on lipids, lipoprotein, Lipases and cholesterol synthesis in the golden hamster. $\mathcal{F}$ Cardiovasc Pharmacol 1989;13:5.

69 Krupp MN, Hoover KW, Valentine JJ. Effects of doxazosin and other antihypertensives on serum lipid levels and lipoprotein lipase in the $\mathrm{C} 578 \mathrm{BR} / \mathrm{cdj}$ mouse. $\mathcal{f}$ Cardiovasc Pharmacol 1989;13/2:S11.

70 Powell JS, Clozel JP, Muller RKM, et al. Inhibitors of angiotensin converting-enzyme prevent myointimal proliferation after vascular injury. Science $1989 ; 245: 186-8$.

71 Aberg G, Ferrer P. Effects of captopril on atheroscerosis in cynomolgus monkeys. F Cardiovasc Pharmacol 1990; 15 (suppl 5):65-72.

72 Chobanian AV, Haudenshild CC, Nickersson C, Drago R. Antiatherogenic effects of captopril in the Watanabe heritable hyperlipidemic rabbit. $f$ Hypertens 1990;15: 327-31.

73 Overturf ML, Sybers HD, Smith SA. Captopril-induced hyperreninaemia in cholesterol-fed rabbits. Res Commun Chem Pathol Pharmacol 1985;47:229-53.

74 The SOLVD Investigators: effect of enalapril on mortality and the development of heart failure in asymptomatic patients with reduced left ventricular ejection fractions. N Engl f Med 1992;327:685-91.

75 The SOLVD Investigators: effect of enalapril on survival in patients with reduced left ventricular ejection fractions and congestive heart failure. Engl 7 Med 1991; 325:293-302.

76 Pfeffer M, Braunwald E, Moye LA, Basta L, Brown EJ, Cuddy TE, Davis BR, et al. Effect of captopril on mortality and morbidity in patients with left ventricular dysfunction after myocardial infarction. $N \mathrm{Engl} f \mathrm{Med}$ 1992:327:669-677.

77 Cleland JGF, Henderson H, McLenachan J, Findlay IN Dargie HJ. Effect of captopril, an angiotensin converting enzyme inhibitor, in patients with angina pectoris and heart failure. $7 \mathrm{Am}$ Coll Cardiol 1991;17:733-9.

78 Prevention of Atherosclerotic Complications with Ketanserin Trial Group. Prevention of atherosclerotic complications: controlled trial with ketanserin. $B M F$ 1989;298:424-30.

79 Schwartz CJ, Valente AJ, Kelley JL, Sprague EA, Edwards EH. Thrombosis and the development of atherosclerosis: Rokitansky revisited. Semin Thromb Hemost 1988;14:189-95.

80 Hackett D, Davies G, Maseri A. Pre-existing coronary stenosis in patients with first myocardial infarction are necessarily severe. Eur Heart $\mathcal{f}$ 1988;9:1317-23.

81 Packham MA, Cazenave JP, Kinlough-Rathbone RL, Mustard JF. Drug effects on platelet adhesion to collagen and damaged vascular walls. Adv Exp Med Biol 1978;109:253-76.

82 Fuster V, Adams PC, Badimon JJ, Chesebro JH. Platelet-inhibitor drugs' role in coronary artery disease. Prog Cardiovasc Dis 1987;29:325-46.

83 Carson SN, Demling RH, Esquivel CO. Aspirin failure in symptomatic atherosclerotic carotid artery disease. Surgery 1981;90:1084-92.

84 Bonchek LI, Boerboom LE, Olinger GN, et al. Prevention of lipid accumulation in experimental vein bypass grafts by antiplatelet therapy. Circulation 1982; 66:338-41.

85 Antiplatelet Trialists Collaboration. Secondary prevention of vascular disease by prolonger antiplatelet treatment. BMF 1988;296:320-31.

86 Chesebro JH, Webster WI, Smith HC, et al. Antiplatelet therapy in coronary disease progression: reduced infarction and new lesion formation [abstract]. Circulation 1989;80 (suppl II):266.

87 Peto R, Gray R, Collins R, Wheatley K, Hennekens C, Jamrozik $\mathrm{K}$, et al. Randomised trial of prophylactic daily aspirin in British male doctors. BMF 1988;296:313-9.

88 Steering Committee of the Physicians' Health Study Research Group. Final report on the aspirin component of the ongoing physicians. $N$ Engl $\mathcal{f}$ Med 1989;321: $130-5$

89 Ridker PM, Manson JE, Buring JE, Goldhaber SZ, Hennekens $\mathrm{CH}$. The effect of chronic platelet inhibition with low-dose aspirin on atherosclerotic progression and acute thrombosis: clinical evidence from the Physicians' Health Study. Am Heart $₹$ 1991;122:1588-92.

90 Hess H, Mietaschk A, Deichsel G. Drug-induced inhibition of platelet function delays progression of peripheral tion of platelet function delays progression of peripheral occlusive arterial disease. A prospective double-blind

91 Janzon L, Bergqvist D, Boberg J, Boberg M, Eriksson I, Lindgarde $\mathrm{F}$, et al. Prevention of myocardial infarction and stroke in patients with intermittent claudication: effects of ticlopidine. Results from STIMS, the Swedish Ticlopidine Multi-centre Study. F Intern Med 1990;227: 301-8.

92 Stiegler H, Hess H, Mietaschk A, Tramppisch HJ, Ingrisch $\mathrm{H}$. Einfluss von Ticlopidin auf die perifere obliteriernde arteriopathie. Dtsch Med Wochenschr 1984; 109:1240-3.

93 Srinivasan A, Aaron S, Chpra PA, Lucas T, Sawyer PN. Effect of thrombotic and antithrombotic drugs on the Effect of thrombotic and antithrombotic drugs on the Surface charge characteristic or canine blood

94 Jaques LB. Heparin. An old drug with a new paradigm. Science 1979;206:528-33.

95 Day CE, Powell JR, Levy RS. Sulfated polysaccharide inhibition of aortic uptake of low density lipoproteins. Artery 1974-1975;1:126-37.

96 Rent R, Nylrman R, Fiedel BA, Gewurz H. Potentiation 
of $\mathrm{Cl}$ esterase inhibitor activity by heparin. Clin Exp Immunol 1976;23:264-71.

97 Packham MA, Cazenave JP, Kinlough-Rathbone RI Mustard JF. Drug effects on platelet adhesion to collaMen and damaged vascular walls. Adv Exp Med Biol gen and damaged

98 Wallis J, Moses JW, Borer JS, Weksler BB, Goldberg $\mathrm{HL}$, Fisher J, et al. Coronary blood flow in coronary artery disease. Heparin-induced potentiation caused by prostacyclin release. Circulation 1982;66 (suppl II):263.

99 Vinazeer H, Sternberger A, Haas S, Blumel E. Influence of heparin, of different heparin fractions, and of low molecular weight heparin-like substances on the mechanism of fibrinolysis. Throm Res 1982;27:341-51.

100 Boyle E, Bragdon JH, Brown RK. Role of heparin in in vitro production of alpha-1-lipoprotein in human plasvitro production of alpha-1-lipoprotein in

101 Graham DM, Lyon TP, Gofman JW, Jones HB, Yankley A, Simonton J, White S. Blood lipids and atherosclerosis. II: the influence of heparin upon lipoprotein metabolism. Circulation 1951;4:666-73.

102 Jaques LB. Drug prophylaxis in atherosclerosis. Artery 1987;14:209-15.

103 Engelberg H, Kuhn R, Steinman M. A controlled study of the effect of intermittent heparin therapy on the course of human coronary atherosclerosis. Circulation 1956;13:489-98
104 Bottiger LE, Carlson LA, Engstedt L, Oro L. Long-term heparin treatment in ischaemic heart disease: effects on clinical condition and plasma lipids. Acta Med Scand 1967;182:245-57.

105 Gertler MM, Leetma H, Koutrouby RJ, et al. Long-term use of mini-dose heparin in post-myocardial infarction. W Adv Exp Med Biol 1975;52:341-50.

106 Neri Serneri GG, Rovelli F, Gensini GF, Pirelli S, T Carnovalli M, Fortini A. Effectiveness of low-dose heparin in prevention of myocardial infarction. Lancet 1987;1:937-42.

107 Hellgren M, Hagnevik K. Blomback M. Heparin aerosol: effect on blood coagulation and pulmonary function. Thromb Res 1981;21:493-502.

108 Borchgrevink CF. Long-term anticoagulant therapy in 0 angina pectoris. A follow up study. Lancet 1962;1: angina 51 .

109 Second Report of the Sixty-Plus Reinfarction Study $\frac{\omega}{D}$ Research Group. Risks of long-term oral anticoagulant $\mathbb{D}$ therapy in elderly patients after myocardial infarction. Lancet 1982;1:64-8.

110 Smith P, Arnesen H, Holme I. The effect of warfarin on mortality and reinfarction after myocardial infarction. $N \vec{O}$ Engl F Med 1990;323:147-52.

111 Meade TW. Low-dose warfarin and low-dose aspirin in the primary prevention of ischaemic heart disease. $A m \mathcal{F}$ Cardiol 1990;65(Suppl C):7-11.

\section{Do coronary angiograms reflect progression of atherosclerosis?}

Are angiographic studies and event counts equally valid in assessing progression of coronary atherosclerosis? The abstract below shows that the first is an independent predicmeasuring a common mechanism for progression and event production, and the most likely contender is thrombosis on plaques.

\section{Coronary disease progression predtcts subsequent cardiac events}

Dovid Waters, I im Craven. Iacques Lesperance

\section{Abstract}

Progression of coronary disease is trequently used as an endpoint in clinical atiats, tet its progrtostic. significance lats not been well documented. Among 383 patients enrolled in such a trial, 335 . undervent repeat cononialy anteriography at 2 years. At stuidy entry all patients were 8,65 yeans of ege, had at least 4 stenoses $3,75 \%$ and had an eiection fraction $>2040$. Coronary lesions were. measured quantitatively using the system of Rethet: et al Progression, defined as an increase in diane. ter stenosis $2.15 \%$, occured in 141 patients $(42 \%)$. Durriag a subsequent follow up of $4, t, 10$ nonths, 107 patients had one or nore cardiac eventst cantiac death (19), MI (36), or revasculant. sation (85). The relative ris $195 \%$ confidence intervals) of patients. With progression, compared with those withoul, was 734 (2)18 247) for car: diac death, $229(1 / 26,4.9)$ for cardige death or
Wi, 1 41 $(0982.03)$ for revascularisation, and $1.69(124,231)$. or any event. The results were similar if progression was defined as a decrease in minimum diander $2.0 .4 \mathrm{~mm}$. The relative inportance of clinical and angiographic vartables was assessed usiag a steptise multivatiable Cox regression nodiel of time to event. Independent predictors were ejection frection $(p=0002)$, progression $(\mathrm{p}$ ) = 00003). IFDL, chotesterol ( $\mathrm{p}=$ 0.005), and livpentension $(p=0.013)$ for cardiac death ejection fraction $(p-0.001)$ and progres. sion ( $\mathrm{p}=0.002$ ) for cardiac death or MI, and pro exessian $(\mathrm{p}=0.04)$, angina $(p=005)$, ejection

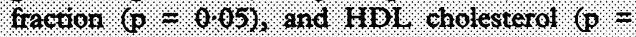
005) for any clintel cvent.

Conctustion Coronany progression is a powerfil. independent predictor of subsequent coronary. events and its use as a suncogate endpoint in clini"

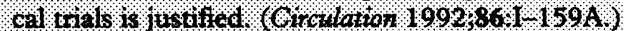

